\title{
Interaction of polymyxin B and A deacilated derivative with monolayers of bacterial lipids
}

\author{
A. Clausell, M. Pujol, M.A. Alsina and Y. Cajal \\ Department of Physical Chemistry, School of Pharmacy, University of Barcelona, \\ Av. Joan XXIII, s/n, 08028 Barcelona, Spain
}

\begin{abstract}
Polymyxin B $(\mathrm{PxB})$ is a polycationic peptide antibiotic produced by gram-positive bacteria Bacillus polymyxia, and is highly selective against gram-negative organisms. In the present work we have studied the interaction of $\mathrm{PxB}$ and PxB-nonapeptide (NP), with lipid monolayers of a lipidic extract from Escherichia coli, a bacteria susceptible to PxB. Kinetics of insertion of both peptides at different surface pressures are compared. Also, the effect of peptides on the phase behaviour of the monolayers is determined from the compression isotherms.
\end{abstract}

\section{INTRODUCTION}

Polymyxin B (PxB) (figure 1-a) is a cyclic amphipathic decapeptide with five positively charged side chains and an acyl chain at the N-terminus [1]. It is produced by Grampositive Paenibacillus polymyxa and it is highly selective against Gram-negative organisms. Polymyxins have been in prevalent use for several decades, however there is no indication of the antibiotic resistance in clinical isolates. They act on membranes, yet the antibacterial mechanism is not stablished. Binding of PxB to surface lipolysaccharides, and consequent disruption of the outer membrane of Gram-negative organisms [2] to permit their entry into periplasmatic space of gram-negative organisms, is a necessary but not a sufficient condition for the antimicrobial effect; $\mathrm{PxB}$ nonapeptide (NP) (figure 1-b) disrupts the outer membrane but it is not an antibiotic $[2,3]$.

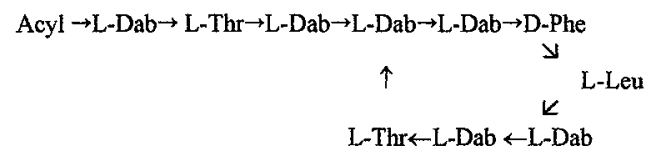

Figure 1-a. Polymyxin B

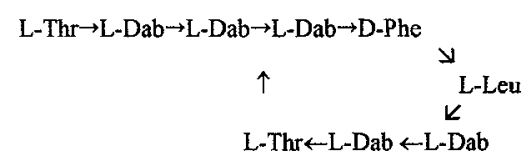

Figure 1-b. Polymyxin B nonapeptide

Studies with model membranes have provided compelling evidence that these cationic peptides interact with anionic phospholipid of bacterial membranes, yet they are not 
ionophores. They induce leakage of the cytoplasmic contents at significantly higher concentrations than the antimicrobial concentrations [4].

In the present work we have studied the interaction of PxB and PxB-nonapeptide (NP), with lipid monolayers of a lipidic extract from Escherichia coli, a bacteria susceptible to PxB. Kinetics of insertion of both peptides at different surface pressures are compared. Also, the effect of peptides on the phase behaviour of the monolayers is determined from the compression isotherms.

\section{MATERIALS AND METHODS}

\subsection{Materials}

Polymyxyn B (PxB) and PxB nonapeptide were purchased from Sigma Aldrich (St. Louis, Mo,USA). E. coli total lipid extract (57,5\% phosphatidylethanolamine (PE), $15,1 \%$ of phophatidylglycerol (PG), 9,8\% cardiolipin (CL) and $17,0 \%$ others) was obtained from Avanti Polar Lipids (Alabaster, Al. USA).

Spreading solvent was chloroform. Lipid films were prepared from chloroform solutions of approximate concentration of $1 \mathrm{mg} \cdot \mathrm{ml}^{-1}$. Monolayers were spread on 10 mM TRIS (tris[hydroxymethyl]amino-methane) buffer subphase, $\mathrm{pH}=8.0$.

\subsection{Methods}

Monolayer studies were performed on a NIMA technology Langmuir film balance equipped with a Wilhemy plate, a pression sensor PS4, a ST 9000 tensiometer and a software trough. The temperature of the experiments was always $21 \pm 0.5^{\circ} \mathrm{C}$.

\subsubsection{Surface activity measurements}

These experiments were performed in a cylindrical trough (70 ml volume) with mechanical stirring. The trough was filled with $10 \mathrm{mM}$ TRIS buffer solution, $\mathrm{pH} 8,0$, and increasing volumes of concentrate antibiotic solutions were injected directly underneath through a lateral hole. Pressure increase was recorded continuously for 120 min. Each run was carried out in triplicate and reproducibility was usually within 0.1 $0.2 \mathrm{mN} \cdot \mathrm{m}^{-1}$ 


\subsubsection{Penetration kinetics}

The same conditions mentioned above were used but for this case a lipid monolayer was present at the air-water interface. Monolayers of $\mathrm{E}$. coli extract were formed spreading lipidic solutions in chloroform to reach a required initial pressure of $5,10,20$ or 32 $\mathrm{mN} \cdot \mathrm{m}^{-1}$.

\subsubsection{Compression isotherms}

The compression isotherms were carried on a PTFE trough of surface area $525 \mathrm{~cm}^{2}$ and volume $240 \mathrm{~cm}^{3}$. Monolayers of E. coli extract were formed by applying small drops of the spreading solutions on the $10 \mathrm{mM}$ TRIS buffer subphase ( $\mathrm{pH}=8.0$ ) with a microsyringe (Hamilton Co, Reno, USA). After five minutes, the monolayers were continuously compressed (symetrical compression) with an area reduction rate of 80 $\mathrm{cm}^{2} \cdot \mathrm{min}^{-1}$. The films were compressed up to their collapse pressure. Each run was repeated three times and standard deviation was typically $<0.5 \%$.

\section{RESULTS AND DISCUSSION}

\subsection{Surface activity}

$\mathrm{PxB}$ when injected in an aqueous subphase modified the surface pressure of the system in a concentration dependent way while NP showed a very low surface activity that was independent of the peptide concentration in the subphase (fig. 1). From these values the surface excess was calculated applying the Gibbs equation:

$$
\Gamma=\Delta \pi /(\mathrm{RT} \Delta \mathrm{lnc}) \quad\left(\mathrm{mol} / \mathrm{m}^{2}\right)
$$

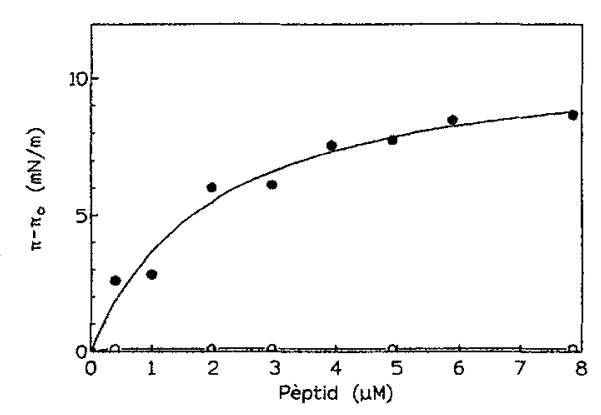

Fig. 1. Surface activity of $\mathrm{PxB}(\bullet)$ and NP (0). Results in the figure correspond to 80 minutes after injection.

where $\mathrm{R}$ is $8.31 \times 10^{5} \mathrm{mN} . \mathrm{cm} . \mathrm{K}^{-1} \cdot \mathrm{mol}^{-1}, \mathrm{~T}$ is the temperature $(\mathrm{K}), \Delta \Pi$ is the surface pressure increase and $\mathrm{c}$ is the molar concentration and are given in table 1 . 


\begin{tabular}{ccc}
\hline $\operatorname{PxB}(\mu \mathrm{M})^{\mathrm{a}}$ & $\Delta \pi(\mathrm{mN} / \mathrm{m})^{\mathrm{b}}$ & $\Gamma\left(\mathrm{mol} / \mathrm{m}^{2}\right)^{\mathrm{c}}$ \\
\hline 0.4 & 2.6 & $1.75 \times 10^{-7}$ \\
1.0 & 2.8 & $1.63 \times 10^{-7}$ \\
2.0 & 6.0 & $3.18 \times 10^{-7}$ \\
3.0 & 6.2 & $3.12 \times 10^{-7}$ \\
4.0 & 7.5 & $3.64 \times 10^{-7}$ \\
5.0 & 7.7 & $3.64 \times 10^{-7}$ \\
5.9 & 8.5 & $3.94 \times 10^{-7}$ \\
7.8 & 8.7 & $3.91 \times 10^{-7}$ \\
\hline
\end{tabular}

Table 1: Surface activity of PxB in TRIS $10 \mathrm{mM}$ pH 8.0 buffer. ${ }^{2}$ PxB concentrations in the subphase;

${ }^{b}$ Surface pressure increase at 80 minutes from PxB injection; ${ }^{c}$ Surface excess.

\subsection{Penetration kinetics}

After injection of $\mathrm{PxB}$ beneath monolayers a clear insertion process was detected (fig. 2). As expected, there was a strong dependence of the maximum surface increase achieved

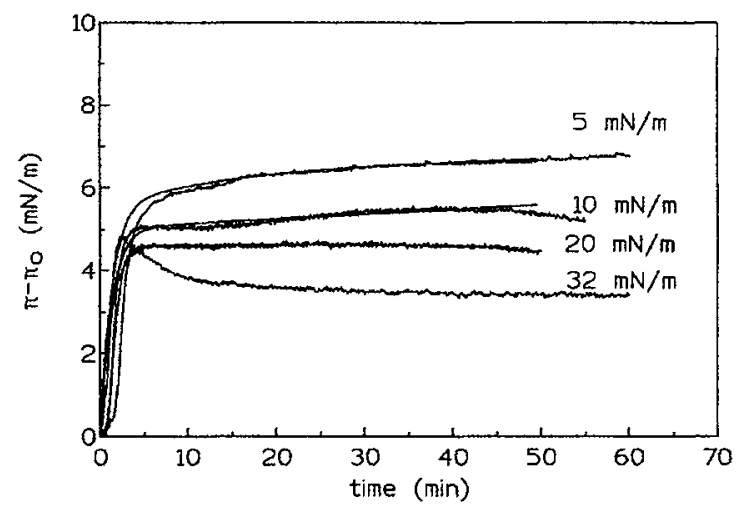

Fig. 2. Pressure increase recorded after injection of $\mathrm{PxB}$ solution under E.coli total extract monolayers spread at 5, 10,20 and $30 \mathrm{mN} \cdot \mathrm{m}^{-1}$. 
on the initial monolayer surface pressure, but pressure increase were lower than those obtained in absence of monolayer. The monolayer in fact acts as a barrier hindering the incorporation of antibiotic molecules into the surface. The insertion process can be analysed by iterative least-square fit to $\Delta \pi=\mathrm{A} \cdot\left(1-\mathrm{e}^{-k} \mathrm{l}^{\mathrm{t}}\right)+\mathrm{B} \cdot\left(1-\mathrm{e}^{-k} 2^{\mathrm{t}}\right)$ where $\mathrm{A}$ and $\mathrm{B}$ are the $\Delta \pi$ corresponding to two processes, with half times of $0.69 / \mathrm{k}_{1}$ and $0.69 / \mathrm{k}_{2}$, respectively, being $k_{1}$ and $k_{2}$ the specific rate constants for each process. Results are summarised in table 2 . When the NP was injected no changes in the surface pressure was observed. That indicates the inability of NP to insert in the E. coli extract monolayer.

\begin{tabular}{cccc}
\hline$\pi_{\mathrm{i}}(\mathrm{mN} / \mathrm{m})$ & $\mathrm{t}_{1 / 2}(\mathrm{~min})=0.69 / k_{1}$ & $\mathrm{t}_{1 / 2}(\mathrm{~min})=0.69 / k_{2}$ & $r^{2}$ \\
& $(\mathrm{~A})$ & $(\mathrm{B})$ & \\
\hline 5 & $0.92(82 \%)$ & $15.30(18 \%)$ & 0.994 \\
10 & $0.90(100 \%)$ & $-\cdots$ & 0.953 \\
20 & $0.85(100 \%)$ & $-\cdots$ & 0.969 \\
32 & $\ldots-$ & - & $\cdots$ \\
\hline
\end{tabular}

Table 2. Kinetic parameters for the insertion of $\mathrm{PxB}$ in $E$. coli total extract monolayers at different surface pressures.

\subsection{Compression isotherms}

The studies performed using compression isotherms let us to check the ability of the $E$. coli lipid extract to produce a stable monolayer with pressure collapse at $49 \mathrm{mN} \cdot \mathrm{m}^{-1}$. The monolayer compressibility indicates that for area values until $360 \AA$. olec $^{1}$ the monolayer present a gas phase behaviour and for minor values are the liquid-expanded state until to collapse pressure. The presence of $\mathrm{PxB}$ in the subphase at $2 \mu \mathrm{M}$ concentration produced an expansion of the monolayer indicative that an insertion process is produced. The collapse pressure remains constant at $49 \mathrm{mN} \cdot \mathrm{m}^{-1}$. Similar behaviour was described before for derivative lipopeptidic antigens of hepatitis $A$ viruses [5]. When NP at the same concentration was injected in the subphase no changes in the $E$. coli lipid extract monolayer were observed. These results are 
indicative of the importance of hydrophobic interaction over electrostatic attractions and can be seen in figure $3 \mathrm{~A}$ and $\mathrm{B}$.
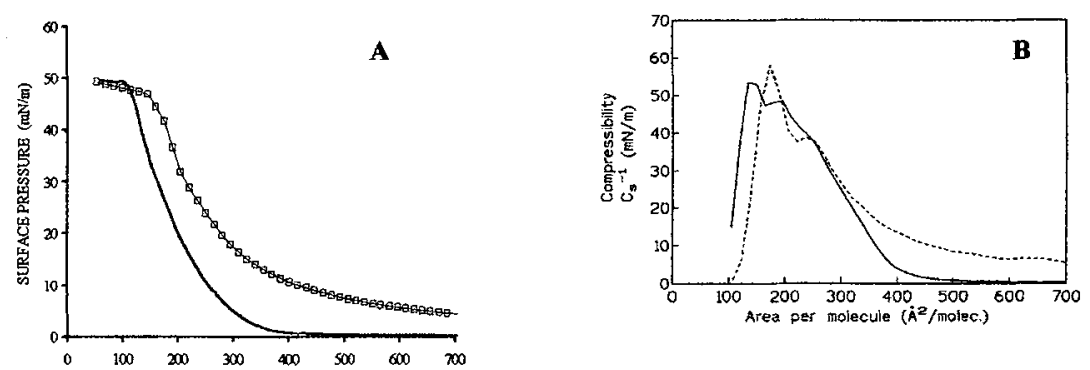

Area per molecule $\left(\AA^{2} /\right.$ molec. $)$

Fig. 3. A: Compression isotherms of $E$. coli lipid extract on $10 \mathrm{mM}$ TRIS buffer, $\mathrm{pH}=8.0$, subphase (-) and when the PxB at $2 \mu \mathrm{M}$ concentration are present in the subphase ( $\square$ ). When NP was in the subphase the compression isotherm is the same as $E$. coli lipid extract $(-)$. B: Compressibility, $\mathrm{C}_{\mathrm{s}}^{-1}$ $(\mathrm{mN} . / \mathrm{m})$, of a monolayer of $E$. coli lipid extract on TRIS buffer $\mathrm{pH}=8.0$ subphase and when the $\mathrm{PxB}$ at $2 \mu \mathrm{M}$ concentration was present in the subphase ( $\cdots)$. When $\mathrm{NP}$ at $2 \mu \mathrm{M}$ was present in the subphase the compressibility of the monolayer are the same as $E$. coli lipid extract $(-)$.

\section{REFERENCES}

[1] R. T. Apitz-Castro, M. K. Jain, G.H. DeHaas, Biochim. Biophys. Acta, 688 (1982) 349-356.

[2] D.R. Storm, K.S. Rosenthal, P.E. Swanson, Ann. Rev. Biochem., 46 (1977) 723-763.

[3] P. Kubesch, J. Boggs, L. Luciano, G. Maass, B. Tummler, Biochemistry, 26 (1987) 2139 - 2149.

[4] Y. Cajal, O.G.Berg, M.K. Jain, Bichem. Biophys. Res. Commm. 210 (1995) 746-752.

[5] A. Chávez, M. Pujol, I. Haro, M.A. Alsina, Y. Cajal, Biopolymers, 58 (2001) 63-77. 